\title{
Occurrence and distribution of fungi associated with grapevine decline in Kurdistan region-Iraq
}

\author{
Raed A. Haleem ${ }^{1}$, Samir K. Abdullah ${ }^{2^{*}}$ and Jaladat M. S. Jubrael ${ }^{3}$ \\ ${ }^{1}$ Plant Protection Department, Faculty of Agriculture and Forestry, University of Duhok, Iraq \\ $2^{*}$ Department of Biology, Faculty of Science, University of Zakho, Iraq \\ ${ }^{3}$ Scientific Research Center, University of Duhok, Iraq \\ *For correspondence: samer_abdalh@yahoo.com
}

\begin{abstract}
A survey was carried out in five locations representing the main grapevine production areas of Duhok governorate-Iraq during 2008-2009 in four seasons, winter (Dec.- Feb.), spring (Mar.May.), summer (Jun. - Aug.), and fall (Sept. - Nov.) Decline symptoms on grapevines included plants that failed to thrive normal, with reducing shoot growth and chlorotic interveinal areas that later became necrotic. In a cross section of grapevine arms, the internal wood tissues were frequently dark brown to black with a wedge-shaped necrotic sector. Severe symptoms were noted during spring to summer almost in all locations. Canes (bark and wood), buds, trunks or arms (bark and wood), and roots were sampled for fungal isolation. Fungal pathogens belonging to 18 genera were isolated from green growth and roots of the grapevine samples during the four seasons. Cylindrocarpon destructans, Neofusicoccum parvum, and Tognignia minima were the main trunk pathogens found in all grape-growing regions. These three species were reported for the first time in Iraq. N. parvum was isolated with a high frequency $(98-100 \%)$ from wood of arms and canes in Bajelor and Badi locations during summer and fall. T. minima was found commonly in Zawita by $37-75 \%$ of isolation in the wood of arms and canes during fall. $C$. destructans was the most dominant root rot fungus and was frequently isolated from almost all locations particularly in Badi (41-75\% of isolation).
\end{abstract}

Key words: Fungal pathogens, Vitis vinifera, Occurence, , Iraq

\section{INTRODUCTION}

Duhok Province is the largest grapevine (Vitis vinifera) producer in Iraq. In 2003, 48000 hectares were grown, which yielded an average of 265000 tons of grapes (F.A.O., 2003). In recent years, reports from grape growers on the incidence of grapevine wood and root fungi have been increasing. Symptoms of vine decline have been described in most of the grapevine production areas around the world, such as California (Scheck et al., 1998b), Portugal (Rego et al., 2000), France (Larignon and Dubos, 2000), Australia (Edwards et al., 2001), Greece (Rumbos and Rumbou, 2001) and South Africa (Halleen et al., 2003). In Iraq, no systematic study has been carried out to determine the fungi associated with vine decline. Decline symptoms on grapevine generally follow a similar pattern of development. During the first years after planting, affected grapevines grow slowly. Symptoms of the disease are: reduced vigour, shortened internodes, reduced foliage, chlorotic leaves and reduced leaf size, frequently leading to death (Scheck et al., 1998a; and Rego et al., 2000).

Larignon and Dubos (1997) concluded that Phaeoacremonium aleophilum and Phaeomoniella chlamydospora were pioneering fungi that colonized living wood, thus preparing the wood for further colonization by the basidiomycete fungi, which were responsible for the typical decay associated with esca. Mugnai et al. (1999) reported the occurrence of the different fungal species at different stages of wood decay and decay progression. Esca, also known as black measles, which is commonly associated with mature vines caused by Phaeoacremonium aleophilum (Togninia minima) as well as other species of Phaeoacremonium shows a range of symptoms from severe to mild or chronic (Edwards et al., 2001; and Gubler et al., 2004a). 
Several species of Botryosphaeria readily infect wounds, and in the case of grapevines this is especially true for pruning wounds (Castillo-Pando et al. 2001; and Phillips, 2002). A symptom that is often associated with Botryosphaeria species is bud mortality, which leads directly to a reduction in yield. Bud mortality is often the result of young shoots being infected by the fungus early in the season. The infection develops into elongated black lesions on the internodes. These infections might lead to shoot dieback as infected shoots become swollen at the base, with the blackened cortex eventually rupturing. These shoots are consequently very brittle and may easily collapse due to their own weight. (Phillips, 1998).

Auger et al. (1999) observed dark streaking of vascular elements in roots of 'Flame Seedless' vines inoculated with Cylindrocarpon sp. Larignon (1999) described symptoms similar to Sweetingham (1983) where diseased vines characteristically displayed abnormal, weak vegetation and in some cases did not sprout at all. Often shoots also dried and died during summer. Furthermore, below-ground symptoms included abnormal root development characterized by shallow growth parallel to the soil surface (Haleen et al., 2006).

The objective of this study was study the spatial and temporal distribution of fungi associated with grapevine decline phenomenon.

\section{MATERIALS AND METHODS}

Field survey: A survey was carried out in five grapevines yards of Duhok governorate during four seasons, winter (Dec - Feb), spring (Mar. May) and summer (Jun. - Aug.), and fall (Sept. Nov.) during 2008-2009. Locations are Nizarke, Berebahar, Zawita, Bajelor, and Badi which were varied in grapevine cultivars, cultivation and training methods.

Field survey was done by surveying $60-80$ plant parts from each location. Central point of the grape vineyard was selected, four directions were The frequency of each isolate was determined as follows:-

$$
\% \text { isolated fungus }=\frac{\text { Colony no. of isolated fungus/plate }}{\text { Total no. of colonies/plate }} \times 100
$$

Fungal isolation from complete vine tissues: Complete vine tissues were sampled, from cane (bark and wood), bud, trunk or arm (bark and wood), leaves, clusters and roots. Small pieces of tissue from the margin between necrotic and apparently healthy tissue were surface sterilized by placing in $70 \%$ ethanol for $30 \mathrm{~s}, 1 \% \mathrm{NaOCl}$ for $1 \mathrm{~min}$ and again in $70 \%$ ethanol for $30 \mathrm{~s}$ and then dried by filter papers. Sterilized tissues pieces were plated onto $2 \%$ potato dextrose agar (PDA) (Himedia Laboratories Pvt. Ltd. - India) containing $0.25 \mathrm{mg} / \mathrm{ml}$ chloramphenicol. Hyphae growing out from the tissue pieces were cut and subcultured onto fresh PDA plates, and incubated at $25 \pm 2{ }^{\circ} \mathrm{C}$ (Van Niekerk et al, 2004). Sporulation was enhanced by culturing the isolates on $2 \%$ water agar bearing pieces of autoclaved grapevine canes at $25{ }^{\circ} \mathrm{C}$ with a $12 / 12 \mathrm{~h}$ photoperiod (Luque et al., 2005).
The layout of the trail was factorial in a Complete Randomized Design (CRD) with three replications. The data obtained from this trial were converted to arcsine and analyzed using SAS program and means were compared using Duncan's multiple range test (SAS Institute Inc., Gary, NC, USA, 1999) 
Phenotypical characterization: All isolates were grown on PDA and MEA at $25^{\circ} \mathrm{C}$ in darkness or under NUV + fluorescent illumination with a 12-h photoperiod (Philips /36W) for 10 - 15 days until cultures sporulated. Isolated fungi were identified based on the characters in culture and on natural substrates (Ellis, 1971; Domsch et al, 1980; Boerema, 1993; Crous et al, 1996; Samson et al, 2000; Watanabe, 2002; Phillips, 2002; Petit and Gubler, 2005; Mostert et al .2005a,b; and UrbezTorres, 2006).

1) Botryosphaeria parva: seven isolates from different locations were used for morphological characterization. In order to enhance sporulation, cultures were placed on $2 \%$ water agar containing autoclaved grapevine wood chips and incubated at $25^{\circ} \mathrm{C}$ under intermittent light $(12 \mathrm{~h})$ (Luque et al, 2005).Isolates were examined weekly for formation of pycnidia and conidia. Conidial morphology (shape, color, and presence or absence of septa) from pycnidia was recorded using a compound microscope .The length and width of 40 conidia were measured.

2) Cylindrocarpon destructans: Colonies grown on PDA for 10 days were further incubated for 20 days to determine the presence or absence of chlamydosporcs. The diameter of 20 chlamydospores per isolate was measured. Length and width of 40 conidia (microconidia and one-, two-, and three-septate macroconidia) were measured.

3) Phaeoacremonium aleophilum: The morphological and cultural characters that were recorded included phialide shape (Type I, II and III), mycelia texture, conidia and conidiophore length. The length and width of 40 conidia and phialides were measured for each isolate.

\section{RESULTS AND DISCUSSON}

Field survey: Field survey was carried out at five locations (Badi, Barebahar, Bajelor, Nizarke and Zawita). Decline symptoms associated with grapevine included plants that failed to thrive, with reduced shoot growth and small leaves with chlorotic interveinal areas that later became necrotic of leaf margines. Severely diseased vines died. In a cross section of grapevine arms, internal wood tissues were partially dark brown to black discoloration with a wedge-shaped necrotic sectors, and later only a small wedge of tissue remain alive. However, death of the vines parts occured when the remaining tissue was killed by the growth of the pathogen. Fungi commonly associated with these symptoms were Phaeoacremonium spp. (W. Gams, Crous and M. J. Wingfield) (causal agents of Esca disease), and Botryosphaeria spp. Ces. \& De Not. (causal agent of perennial canker) as well as, Eutypa lata (Pers.) Tul. \& C. Tul. and Cylindrocarpon spp. (Zins.) Scholten (causal agent of black foot disease) (Armengol et al., 2001; Creaser and Wicks, 2001; and Oliveira et al., 2004).

In Beribahar location, Rashmew cv. grown on heading system was the most affected one compared with the other locations. The disease incidence (Table 1) was $37.5 \%$ with severity of 0.15 during spring, and then increased during summer and the highest disease severity reached 0.36 . This might be due to the cultivar susceptibility, training method soil $\mathrm{pH}$, and soil drought. Saido (2007) found that the decline severity of Rashmew cultivar grown on heading training system was more severe than other training systems. In Badi location, the disease development on Kamali cv. grown on T-shape system was not prominent and represent as the lesser one. The diseases severity ranged between $0.15-0.16$ throughout survey period, there was increase in the disease incidence augmented to $50 \%$ in summer.

Table (1): Disease severity and incidence of three grapevine cultivars during spring (May) and summer (August) 2009 at Duhok governorate.

\begin{tabular}{|c|c|c|c|c|c|c|}
\hline \multirow[t]{2}{*}{ Location } & \multirow[t]{2}{*}{ Cultivar } & \multirow{2}{*}{$\begin{array}{l}\text { Training } \\
\text { method }\end{array}$} & \multicolumn{2}{|c|}{ Spring/May } & \multicolumn{2}{|c|}{ Summer/ August } \\
\hline & & & Dis. incidence & Dis. severity & Dis. incidence & $\begin{array}{l}\text { Dis. } \\
\text { Severity }\end{array}$ \\
\hline Badi & Kamali & T-shape & $37.5 \%$ & 0.15 & $50 \%$ & 0.16 \\
\hline Bajelor & Taefi & Wiring & $12.5 \%$ & 0.03 & $75 \%$ & 0.31 \\
\hline Berebahar & Rashmew & Heading & $37.5 \%$ & 0.15 & $67.5 \%$ & 0.36 \\
\hline Nizarke & Rashmew & Heading & $10 \%$ & 0.03 & $62.5 \%$ & 0.24 \\
\hline Zawita & Rashmew & Heading & $15 \%$ & 0.04 & $75 \%$ & 0.25 \\
\hline
\end{tabular}


Fungal Isolation from complete vines tissues: Badi location: Mycological analysis showed that 18 fungal genera were isolated from green growth and roots of the grapevine samples during four seasons (Table 2). During winter (Dec.-Feb.), the most dominant fungus was Botryosphaeria parva Pennycook and Samuels (Anamorph: Neofusicoccum parvum), being isolated from the arms', canes' wood, and buds by $87.02 \%, 75.04 \%$, and $91.53 \%$ respectively with significant difference from other fungi. The high occurrence of the fungus $(40 \%)$ in the arms of old grapevines was also recorded by Martin and Cobos (2007) in Castillay Leaon - Spain. Neosytalidium dimidiatum (Penz.) Crous \& Slippers who detected it by $12.98 \%$ in canes' wood, while Phoma spp. was detected by $75 \%$ in canes' bark. The most common root rot fungus isolated during this period was Cylindrocarpon destructans (75.11\%).

Table (2): Frequency of isolated fungi from different grapevine parts in four seasons at Badi location.

\begin{tabular}{|c|c|c|c|c|c|}
\hline Plant part & Isolated fungus & $\begin{array}{l}\text { (Winter) } \\
\text { Dec. - Feb. }\end{array}$ & $\begin{array}{l}\text { (Spring) } \\
\text { Mar. - May }\end{array}$ & $\begin{array}{l}\text { (Summer) } \\
\text { June - Aug. }\end{array}$ & $\begin{array}{l}\text { (Fall) } \\
\text { Sept. - Nov. }\end{array}$ \\
\hline Arms' bark & $\begin{array}{l}\text { A. alternata } \\
B . \text { parva } \\
\text { Cl. elatum } \\
\text { N. dimidiatum } \\
\text { U. atrum } \\
\text { Others }\end{array}$ & $\begin{array}{l}2.37 \mathrm{~m}-\mathrm{z} \\
31.03 \mathrm{~g}-\mathrm{k} \\
0 . \mathrm{n}-\mathrm{z} \\
3.02 \mathrm{~m}-\mathrm{B} \\
0 \mathrm{n}-\mathrm{z} \\
46.65 \mathrm{~d}-\mathrm{g}\end{array}$ & $\begin{array}{ll}0 & n-z \\
0 & n-z \\
0 & n-z \\
0 & n-z \\
0 & n-z \\
25 & g-m \\
\end{array}$ & $\begin{array}{l}3.71 \quad \mathrm{l}-\mathrm{z} \\
25 \mathrm{~g}-\mathrm{n} \\
0 \mathrm{n}-\mathrm{z} \\
0 \mathrm{n}-\mathrm{z} \\
4.15 \mathrm{I}-\mathrm{z} \\
0 \mathrm{n}-\mathrm{z}\end{array}$ & $\begin{array}{l}13.73 \text { h-y } \\
0 \mathrm{n}-\mathrm{z} \\
4.15 \mathrm{l}-\mathrm{z} \\
0 \mathrm{n}-\mathrm{z} \\
13.73 \mathrm{~h}-\mathrm{y} \\
0 \mathrm{n}-\mathrm{z}\end{array}$ \\
\hline Arms' wood & $\begin{array}{l}\text { A. alternata } \\
B . \text { parva } \\
P . \text { aleophilum } \\
\text { Phoma spp. } \\
\text { N. dimidiatum } \\
\text { Others }\end{array}$ & $\begin{array}{l}0 \mathrm{n}-\mathrm{z} \\
87.02 \text { a-c } \\
0 \mathrm{n}-\mathrm{z} \\
0 \mathrm{n}-\mathrm{z} \\
12.97 \mathrm{~h}-\mathrm{z} \\
0 \mathrm{n}-\mathrm{z}\end{array}$ & $\begin{array}{l}0 \mathrm{n}-\mathrm{z} \\
70.79 \mathrm{~b}-\mathrm{e} \\
9.80 \mathrm{j}-\mathrm{z} \\
0 \mathrm{n}-\mathrm{z} \\
1.95 \mathrm{~m}-\mathrm{z} \\
0 \mathrm{n}-\mathrm{z} \\
\end{array}$ & $\begin{array}{l}0 \mathrm{n}-\mathrm{z} \\
6.70 \mathrm{j}-\mathrm{z} \\
27.69 \mathrm{~g}-\mathrm{l} \\
13.73 \mathrm{~h}-\mathrm{w} \\
0 \mathrm{n}-\mathrm{z} \\
13.48 \mathrm{~g}-\mathrm{k}\end{array}$ & $\begin{array}{l}0 \mathrm{n}-\mathrm{z} \\
98.04 \mathrm{a} \\
1.95 \mathrm{~m}-\mathrm{z} \\
0 \mathrm{n}-\mathrm{z} \\
0 \mathrm{n}-\mathrm{z} \\
0 \mathrm{n}-\mathrm{z} \\
\end{array}$ \\
\hline Canes' bark & $\begin{array}{l}\text { A. alternata } \\
\text { B. parva } \\
\text { P. aleophilum } \\
\text { Phoma spp. } \\
\text { N. dimidiatum } \\
\text { Others } \\
\end{array}$ & $\begin{array}{l}0 \quad n-z \\
0 \quad n-z \\
0 \quad n-z \\
75 \text { b-d } \\
0 \quad n-z \\
25 \text { g-r }\end{array}$ & 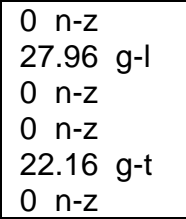 & $\begin{array}{ll} & n-z \\
0 & n-z \\
0 & n-z \\
0 & n-z \\
0 & n-z \\
0 & n-z\end{array}$ & $\begin{array}{l}0 \mathrm{n}-\mathrm{z} \\
44.34 \mathrm{~d}-\mathrm{h} \\
9.80 \mathrm{j}-\mathrm{z} \\
0 \mathrm{n}-\mathrm{z} \\
0 \mathrm{n}-\mathrm{z} \\
25 \mathrm{~g}-\mathrm{m}\end{array}$ \\
\hline Canes' wood & $\begin{array}{l}\text { A. alternata } \\
B . \text { parva } \\
\text { N. dimidiatum } \\
\text { U. atrum } \\
\text { Others }\end{array}$ & $\begin{array}{l}0 \mathrm{n}-\mathrm{z} \\
75.04 \mathrm{~b}-\mathrm{d} \\
12.98 \mathrm{~h}-\mathrm{z} \\
2.37 \mathrm{n}-\mathrm{z} \\
0 \mathrm{n}-\mathrm{z}\end{array}$ & $\begin{array}{l}0 \mathrm{n}-\mathrm{z} \\
66.82 \text { b-e } \\
33.16 \mathrm{f}-\mathrm{j} \\
0 \mathrm{n}-\mathrm{z} \\
0 \mathrm{n}-\mathrm{z}\end{array}$ & $\begin{array}{l}10.44 \mathrm{i}-\mathrm{z} \\
84.63 \mathrm{a}-\mathrm{c} \\
0 \mathrm{n}-\mathrm{z} \\
0 \mathrm{n}-\mathrm{z} \\
2.37 \mathrm{~m}-\mathrm{z}\end{array}$ & $\begin{array}{l}0 \mathrm{n}-\mathrm{z} \\
1.14 \mathrm{~m}-\mathrm{z} \\
0 \mathrm{n}-\mathrm{z} \\
0 \mathrm{n}-\mathrm{z} \\
0 \mathrm{n}-\mathrm{z}\end{array}$ \\
\hline Bud & $\begin{array}{l}\text { A. alternata } \\
B . \text { parva } \\
\text { Cl. elatum } \\
\text { P. aleophilum } \\
\text { Phoma spp. } \\
\text { N. dimidiatum } \\
\text { Others }\end{array}$ & $\begin{array}{l}5.12 \mathrm{k}-\mathrm{z} \\
91.53 \mathrm{ab} \\
0 \mathrm{n}-\mathrm{z} \\
0 \mathrm{n}-\mathrm{z} \\
0 \mathrm{n}-\mathrm{z} \\
0 \mathrm{n}-\mathrm{z} \\
2.37 \mathrm{~m}-\mathrm{z}\end{array}$ & $\begin{array}{l}0 \mathrm{n}-\mathrm{z} \\
44.34 \text { d-h } \\
0 \mathrm{n}-\mathrm{z} \\
0 \mathrm{n}-\mathrm{z} \\
0 \mathrm{n}-\mathrm{z} \\
25 \mathrm{~g}-\mathrm{r} \\
9.80 \mathrm{j}-\mathrm{z}\end{array}$ & $\begin{array}{l}0 \mathrm{n}-\mathrm{z} \\
0 \mathrm{n}-\mathrm{z} \\
0 \mathrm{n}-\mathrm{z} \\
0 \mathrm{n}-\mathrm{z} \\
25 \mathrm{~g}-0 \\
0 \mathrm{n}-\mathrm{z} \\
0 \mathrm{n}-\mathrm{z}\end{array}$ & $\begin{array}{l}0 \mathrm{n}-\mathrm{z} \\
8.47 \mathrm{j}-\mathrm{z} \\
2.37 \mathrm{~m}-\mathrm{z} \\
20.00 \mathrm{~g}-\mathrm{u} \\
0 \mathrm{n}-\mathrm{z} \\
0 \mathrm{n}-\mathrm{z} \\
0 \mathrm{n}-\mathrm{z}\end{array}$ \\
\hline Clusters & $\begin{array}{l}\text { A. alternata } \\
P . \text { aleophilum } \\
\text { Others }\end{array}$ & $\begin{array}{ll}0 & n-z \\
0 & n-z \\
0 & n-z\end{array}$ & $\begin{array}{ll}0 & n-z \\
0 & n-z \\
25 & g-r\end{array}$ & $\begin{array}{ll}0 & n-z \\
0 & n-z \\
0 & n-z\end{array}$ & $\begin{array}{l}66.82 \text { b-e } \\
33.33 \text { f-j } \\
0 n-z\end{array}$ \\
\hline Root & $\begin{array}{l}\text { A. alternata } \\
\text { C. destructans } \\
\text { Fusarium spp. } \\
\text { M. phaseolina } \\
P . \text { aleophilum } \\
\text { R. solani } \\
\text { Others }\end{array}$ & $\begin{array}{l}0 \mathrm{n}-\mathrm{z} \\
75.11 \text { b-d } \\
3.49 \mathrm{l}-\mathrm{z} \\
0 \mathrm{n}-\mathrm{z} \\
0 \mathrm{n}-\mathrm{z} \\
0 \mathrm{n}-\mathrm{z} \\
1.96 \mathrm{~m}-\mathrm{z}\end{array}$ & $\begin{array}{l}0 \mathrm{n}-\mathrm{z} \\
40.37 \mathrm{e}-\mathrm{i} \\
7.37 \mathrm{j}-\mathrm{z} \\
0 \mathrm{n}-\mathrm{z} \\
1.96 \mathrm{~m}-\mathrm{z} \\
0.53 \mathrm{~m}-\mathrm{z} \\
7.37 \mathrm{j}-\mathrm{z} \\
\end{array}$ & $\begin{array}{l}0 \mathrm{n}-\mathrm{z} \\
63.90 \mathrm{c}-\mathrm{f} \\
23.28 \mathrm{~g}-\mathrm{s} \\
3.02 \mathrm{~m}-\mathrm{z} \\
0 \mathrm{n}-\mathrm{z} \\
0 \mathrm{n}-\mathrm{z} \\
1.74 \mathrm{~m}-\mathrm{z}\end{array}$ & $\begin{array}{l}6.70 \mathrm{j}-\mathrm{z} \\
69.33 \text { b-e } \\
14.52 \text { h-v } \\
0 \mathrm{n}-\mathrm{z} \\
0 \mathrm{n}-\mathrm{z} \\
0 \mathrm{n}-\mathrm{z} \\
0 \mathrm{n}-\mathrm{z} \\
\end{array}$ \\
\hline
\end{tabular}


During spring (Mar. - May) B. parva was also the most frequent fungus isolated by $70.79 \%$ from arms' wood. In the root of infected Grapevine/Kamali (cv.), C. destructans was isolated by $40.37 \%$ with significant difference from other fungi. The occurrence of $N$. dimidiatum continued during spring by $33.16 \%$ in canes' wood.

During summer, B. parva was observed significantly $(84.63 \%)$ in canes' wood. Phaeoacremonium aleaophilum, Phoma spp. were shown by $27.69 \%$, $13.75 \%$ in arms' wood respectively. C. destructans, Fusarium spp. and Macrophomina phaseolina (Tassi) Goid., were isolated from root by $63.90 \%$., $23.28 \%$ and $3.02 \%$ respectively.

During fall (Sept. - Nov.), Table (2) shows that the highest detection of $B$. parva was observed $(98.04 \%)$ in arms' wood with significant difference from all other fungi. Infected clusters with Alternaria alternata and $P$. aleophilum detected by $66.82 \%, 33.33 \%$ respectively.

Bajelor location: The direct isolation of fungi from Taefi (cv.) was shown in Table (3). During winter, the most common fungus was $B$. parva isolated by $60.63 \%, 74.06 \%$ in canes' wood, and buds respectively. A. alternata was isolated from arms' wood by $68.36 \%$ and $P$. aleophilum from arms' wood and root by $13.95 \%, 17.86 \%$ respectively. In France, the occurrence of $P$. aleophilum in arms' wood of grape was high which shown by $78.2 \%$ (Larignon and dubos, 1997). U. atrum was isolated by $25 \%$ from arms' bark, while Fusarium spp. was isolated by $32.90 \%$ from infected roots.

Table (3): Frequency of isolated fungi from different grapevine parts in four seasons at Bajelor location.

\begin{tabular}{|c|c|c|c|c|c|}
\hline Plant part & Isolated fungus & $\begin{array}{l}\text { (Winter) } \\
\text { Dec. - Feb. }\end{array}$ & $\begin{array}{l}\text { (Spring) } \\
\text { Mar. - May }\end{array}$ & $\begin{array}{l}\text { (Summer) } \\
\text { June - Aug. }\end{array}$ & $\begin{array}{l}\text { (Fall) } \\
\text { Sept. - Nov. }\end{array}$ \\
\hline Arms' bark & $\begin{array}{l}\text { A. alternata } \\
B . \text { parva } \\
P . \text { aleophilum } \\
U \text {. atrum } \\
\text { Others }\end{array}$ & $\begin{array}{l}25 \mathrm{e}-\mathrm{i} \\
0 \mathrm{k}-\mathrm{v} \\
0 \mathrm{k}-\mathrm{v} \\
25 \mathrm{e}-\mathrm{i} \\
0 \mathrm{k}-\mathrm{v}\end{array}$ & $\begin{array}{ll}0 & k-v \\
75 & a \\
0 & k-v \\
0 & k-v \\
0 & k-v\end{array}$ & $\begin{array}{ll}0 & \mathrm{k}-\mathrm{v} \\
0 & \mathrm{k}-\mathrm{v} \\
0 & \mathrm{k}-\mathrm{v} \\
0 & \mathrm{k}-\mathrm{v} \\
0 & \mathrm{k}-\mathrm{v}\end{array}$ & $\begin{array}{l}60.58 \quad b-d \\
0 \mathrm{k}-\mathrm{v} \\
2.37 \mathrm{j}-\mathrm{v} \\
1.95 \mathrm{j}-\mathrm{v} \\
1.95 \mathrm{j}-\mathrm{v}\end{array}$ \\
\hline Arms' wood & $\begin{array}{l}\text { A. alternata } \\
B . \text { parva } \\
\text { Cl. elatum } \\
\text { P. aleophilum } \\
\text { N. dimidiatum } \\
\text { U. atrum } \\
\text { Others }\end{array}$ & $\begin{array}{l}68.36 \text { bc } \\
0 \quad k-v \\
0 \text { k-v } \\
13.95 \text { f-o } \\
0 \text { k-v } \\
0 \text { k-v } \\
20.00 \text { f-p }\end{array}$ & $\begin{array}{l}0 \mathrm{k}-\mathrm{v} \\
69.92 \mathrm{~b} \\
0 \mathrm{k}-\mathrm{v} \\
13.45 \mathrm{f}-\mathrm{r} \\
7.84 \mathrm{~g}-\mathrm{v} \\
0 \mathrm{k}-\mathrm{v} \\
0 \mathrm{k}-\mathrm{v}\end{array}$ & $\begin{array}{l}0 \mathrm{k}-\mathrm{v} \\
100 \mathrm{a} \\
0 \mathrm{k}-\mathrm{v} \\
1.95 \mathrm{j}-\mathrm{v} \\
0 \mathrm{k}-\mathrm{v} \\
0 \mathrm{k}-\mathrm{v} \\
0 \mathrm{k}-\mathrm{v}\end{array}$ & $\begin{array}{l}27.55 \mathrm{e}-\mathrm{h} \\
0 \mathrm{k}-\mathrm{v} \\
1.67 \mathrm{j}-\mathrm{v} \\
8.94 \mathrm{~g}-\mathrm{v} \\
0 \mathrm{k}-\mathrm{v} \\
23.73 \mathrm{e}-\mathrm{j} \\
6.69 \mathrm{~h}-\mathrm{v}\end{array}$ \\
\hline Cane's bark & $\begin{array}{l}\text { A. alternata } \\
\text { B. parva } \\
\text { Cl. Elatum }\end{array}$ & $\begin{array}{l}0 \mathrm{k}-\mathrm{v} \\
25 \mathrm{e}-\mathrm{i} \\
3.02 \mathrm{j}-\mathrm{v}\end{array}$ & $\begin{array}{l}0 \mathrm{k}-\mathrm{v} \\
75 \mathrm{~b} \\
25 \mathrm{e}-\mathrm{i}\end{array}$ & $\begin{array}{l}0 \mathrm{k}-\mathrm{v} \\
75 \mathrm{~b} \\
0 \mathrm{k}-\mathrm{v}\end{array}$ & $\begin{array}{l}77.84 \mathrm{~b} \\
5.12 \mathrm{~h}-\mathrm{v} \\
0 \mathrm{k}-\mathrm{v}\end{array}$ \\
\hline Canes' wood & $\begin{array}{l}\text { A. alternata } \\
B \text {. parva } \\
\text { Cl. elatum } \\
\text { N. dimidiatum } \\
\text { Trichoderma spp. } \\
\text { U. atrum } \\
\text { Others }\end{array}$ & $\begin{array}{l}0 \mathrm{k}-\mathrm{v} \\
60.63 \mathrm{~b}-\mathrm{d} \\
0 \mathrm{k}-\mathrm{v} \\
2.37 \mathrm{j}-\mathrm{v} \\
2.37 \mathrm{j}-\mathrm{v} \\
0 \mathrm{k}-\mathrm{v} \\
5.12 \mathrm{~h}-\mathrm{v}\end{array}$ & $\begin{array}{l}0 \mathrm{k}-\mathrm{v} \\
75 \mathrm{~b} \\
3.02 \mathrm{j}-\mathrm{v} \\
0 \mathrm{k}-\mathrm{v} \\
4.14 \mathrm{i}-\mathrm{v} \\
0 \mathrm{k}-\mathrm{v} \\
9.58 \mathrm{~g}-\mathrm{v}\end{array}$ & $\begin{array}{ll}0 & \mathrm{k}-\mathrm{v} \\
100 & \mathrm{a} \\
0 & \mathrm{k}-\mathrm{v} \\
0 & \mathrm{k}-\mathrm{v} \\
0 & \mathrm{k}-\mathrm{v} \\
0 & \mathrm{k}-\mathrm{v} \\
0 & \mathrm{k}-\mathrm{v}\end{array}$ & $\begin{array}{l}12.24 \mathrm{f}-\mathrm{u} \\
52.37 \mathrm{~b}-\mathrm{e} \\
0 \mathrm{k}-\mathrm{v} \\
0 \mathrm{k}-\mathrm{v} \\
0 \mathrm{k}-\mathrm{v} \\
2.37 \mathrm{j}-\mathrm{v} \\
1.67 \mathrm{j}-\mathrm{v}\end{array}$ \\
\hline Bud & $\begin{array}{l}\text { A. alternata } \\
\text { B. parva } \\
\text { Cl. elatum } \\
\text { U. atrum }\end{array}$ & $\begin{array}{l}16.35 \mathrm{f}-\mathrm{m} \\
74.06 \mathrm{~b} \\
1.97 \mathrm{j}-\mathrm{v} \\
0 \mathrm{k}-\mathrm{v}\end{array}$ & $\begin{array}{ll}25 & \mathrm{e}-\mathrm{i} \\
0 & \mathrm{k}-\mathrm{v} \\
0 & \mathrm{k}-\mathrm{v} \\
0 & \mathrm{k}-\mathrm{v}\end{array}$ & $\begin{array}{ll}0 & \mathrm{k}-\mathrm{v} \\
0 & \mathrm{k}-\mathrm{v} \\
0 & \mathrm{k}-\mathrm{v} \\
0 & \mathrm{k}-\mathrm{v}\end{array}$ & $\begin{array}{l}70.89 \quad b \\
0 \quad k-v \\
0 \quad k-v \\
12.39 \text { f-t }\end{array}$ \\
\hline Leaf & A. alternata & $0 \mathrm{k}-\mathrm{v}$ & $0 \mathrm{k}-\mathrm{v}$ & $0 \mathrm{k}-\mathrm{v}$ & $80 \mathrm{~b}$ \\
\hline Root & $\begin{array}{l}\text { A. alternata } \\
\text { C. destructans } \\
\text { Fusarium spp. } \\
\text { M. phaseolina } \\
P . \text { aleophilum } \\
\text { U. atrum } \\
\text { Others }\end{array}$ & $\begin{array}{ll}0 & k-v \\
0 & k-v \\
32.90 & d-g \\
15.70 & h-v \\
17.86 & f-k \\
0 & k-v \\
0 & k-v\end{array}$ & $\begin{array}{l}0 \mathrm{k}-\mathrm{v} \\
40.01 \mathrm{c}-\mathrm{f} \\
3.02 \mathrm{j}-\mathrm{v} \\
13.73 \mathrm{f}-\mathrm{q} \\
1.44 \mathrm{j}-\mathrm{v} \\
3.02 \mathrm{j}-\mathrm{v} \\
0 \mathrm{k}-\mathrm{v}\end{array}$ & $\begin{array}{l}0 \mathrm{k}-\mathrm{v} \\
1.28 \mathrm{j}-\mathrm{v} \\
7.87 \mathrm{~g}-\mathrm{v} \\
3.66 \mathrm{i}-\mathrm{v} \\
0 \mathrm{k}-\mathrm{v} \\
0 \mathrm{k}-\mathrm{v} \\
15.66 \mathrm{f}-\mathrm{n}\end{array}$ & $\begin{array}{l}12.49 \mathrm{f}-\mathrm{s} \\
27.69 \mathrm{e}-\mathrm{h} \\
16.99 \mathrm{f}-\mathrm{I} \\
8.92 \mathrm{~g}-\mathrm{v} \\
0 \mathrm{k}-\mathrm{v} \\
0 \mathrm{k}-\mathrm{v} \\
10.23 \mathrm{~g}-\mathrm{v}\end{array}$ \\
\hline
\end{tabular}

${ }^{*}$ Means followed by different letters are significantly different based on Duncan's Multiple Range test $(P=0.05)$.

** Others:- Represent the percentage of low frequency fungi counted together, include:- Chaetomium elatum, Stachybotrys spp., Drekeslera spp., Pestalatio spp., Epicocum spp., Papulorspora spp., Penicillium spp. Aspergillus spp. Morphotype 1(Colored mycelium with chlamydospores), Morphotype 2 (Sterile mycelium) . ${ }^{* *}$ Fusarium spp.: Include F. semitectum (Berkeley and Ravenel F. culmorum (W.G. Smith) Saccardo, F. crookwellense Burgess, Nelson and Toussoun, and F. proliferatum (Matsushima) Nirenberg. 
During spring, results revealed that $B$. parva was represent as effective fungi since shown by $66.92 \%$ $75 \%$ in arms' bark, arms' wood, canes' bark, and canes' wood. C. destructans was appeared by $40.01 \%$. During summer, B. parva was ubiquitous and more abundant (100\%) in the wood of arms and canes. During fall, results revealed that $B$. parva occurred significantly by $60.58 \%$ in arms' bark, in addition to $P$. aleaophilum in arms' bark and wood by $12.37 \%$ and $8.94 \%$ respectively.
Berebar location: During winter, the most dominant fungus isolated from arms' bark was Ulocaldium atrum (68.27\%). Cladosporiunm elatum (Harz) Nannf was shown by $24.74 \%$ in canes' wood, whereas $P$. aleophilum and Phoma spp. were detected in arms' wood by $25 \%$ in each. The frequent fungi isolated from infected roots were $C$. destructans and $M$. phaseolina (Table 4).

Table (4): Frequency of isolated fungi from different grapevine parts in four seasons at Berebahar location.

\begin{tabular}{|c|c|c|c|c|c|}
\hline Plant part & Isolated fungus & $\begin{array}{l}\text { (Winter) } \\
\text { Dec. - Feb. }\end{array}$ & $\begin{array}{l}\text { (Spring) } \\
\text { Mar. - May }\end{array}$ & $\begin{array}{l}\text { (Summer) } \\
\text { June - Aug. }\end{array}$ & $\begin{array}{l}\text { (Fall) } \\
\text { Sept. - Nov. }\end{array}$ \\
\hline Arms' bark & $\begin{array}{l}\text { A. alternata } \\
\text { B. parva } \\
\text { U. atrum } \\
\text { Others }\end{array}$ & $\begin{array}{l}0 \mathrm{f} f \\
0 \mathrm{f} \\
68.37 \mathrm{ab} \\
8.47 \mathrm{~d}-\mathrm{f}\end{array}$ & $\begin{array}{l}0 \mathrm{f} \\
0 \mathrm{f} \\
25 \mathrm{~b}-\mathrm{f} \\
0 \mathrm{f}\end{array}$ & $\begin{array}{l}75 \mathrm{a} \\
0 \mathrm{f} \\
2.75 \text { ef } \\
0 \mathrm{f}\end{array}$ & $\begin{array}{l}0 \mathrm{f} \\
0 \mathrm{f} \\
9.80 \mathrm{~d}-\mathrm{f} \\
20.30 \mathrm{c}-\mathrm{f}\end{array}$ \\
\hline Arms' wood & $\begin{array}{l}\text { A. alternata } \\
\text { B. parva } \\
\text { P. aleophilum } \\
\text { Phoma spp. } \\
\text { N. dimidiatum } \\
\text { U. atrum } \\
\text { Others }\end{array}$ & $\begin{array}{l}5.12 \text { ef } \\
5.12 \text { ef } \\
25 \text { b-f } \\
25 \text { b-f } \\
0 \mathrm{f} \\
0 \\
2.37 \text { ef }\end{array}$ & $\begin{array}{l}6.70 \text { ef } \\
75 \text { a } \\
0 \mathrm{f} \\
0 \mathrm{f} \\
237 \text { ef } \\
3.02 \text { ef } \\
0 \mathrm{f}\end{array}$ & $\begin{array}{l}0 \mathrm{f} \\
11.70 \text { d-f } \\
3.02 \text { ef } \\
0 \mathrm{f} \\
0 \mathrm{f} \\
25 \mathrm{~b}-\mathrm{f} \\
25 \mathrm{~b}-\mathrm{f}\end{array}$ & 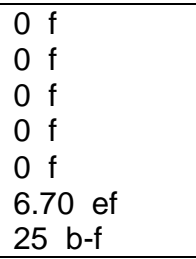 \\
\hline Canes' bark & $\begin{array}{l}\text { A. alternata } \\
\text { B. parva } \\
\text { Cl. elatum } \\
\text { Trichoderma spp. } \\
\text { U. atrum } \\
\text { Others }\end{array}$ & $\begin{array}{l}0 \mathrm{f} \\
3.02 \text { ef } \\
17.86 \mathrm{c}-\mathrm{f} \\
0 \mathrm{f} \\
6.70 \text { ef } \\
0 \mathrm{f}\end{array}$ & $\begin{array}{ll} & 0 f \\
0 & f \\
0 & f \\
0 & f \\
0 & f \\
25 & b-f\end{array}$ & $\begin{array}{l}0 \mathrm{f} \\
0 \mathrm{f} \\
0 \mathrm{f} \\
25 \mathrm{~b}-\mathrm{f} \\
4.15 \text { ef } \\
9.80 \text { d-f }\end{array}$ & $\begin{array}{ll}26.48 \quad b-f \\
0 & f \\
0 & f \\
0 & f \\
0 & f \\
0 & f\end{array}$ \\
\hline Canes' wood & $\begin{array}{l}\text { Cl. Elatum } \\
\text { Others }\end{array}$ & $\begin{array}{l}23.74 \text { b-f } \\
51.71 \text { a-d }\end{array}$ & $\begin{array}{ll}0 & f \\
0 & f \\
\end{array}$ & $\begin{array}{l}0 \mathrm{f} \\
75 \mathrm{a}\end{array}$ & $\begin{array}{l}0 \mathrm{f} \\
34.78 \text { a-e }\end{array}$ \\
\hline Bud & $\begin{array}{l}\text { A. alternata } \\
\text { Cl. elatum } \\
\text { U. atrum } \\
\text { Others }\end{array}$ & $\begin{array}{l}6.70 \text { ef } \\
0 \text { f } \\
10.77 \text { d-f } \\
24.53 \text { b-f }\end{array}$ & $\begin{array}{ll}0 & f \\
0 & f \\
0 & f \\
0 & f\end{array}$ & $\begin{array}{l}0 f f \\
0 f f \\
50 \text { a-f } \\
0 f\end{array}$ & $\begin{array}{l}34.20 \text { a-e } \\
17 \mathrm{c} \text {-f } \\
1.66 \text { ef } \\
6.70 \text { ef }\end{array}$ \\
\hline Leaf & $\begin{array}{l}\text { A. alternata } \\
\text { Trichoderma spp. } \\
\text { Cl. elatum } \\
\text { U. atrum } \\
\text { Others }\end{array}$ & $\begin{array}{ll}0 & f \\
0 & f \\
0 & f \\
0 & f \\
0 & f\end{array}$ & $\begin{array}{l}0 f \\
0 f f \\
0 f f \\
0 f \\
0 f\end{array}$ & $\begin{array}{l}11.49 \mathrm{~d}-\mathrm{f} \\
25 \mathrm{~b}-\mathrm{f} \\
0 \mathrm{f} \\
11.45 \mathrm{~d}-\mathrm{f} \\
10.36 \mathrm{~d}-\mathrm{f}\end{array}$ & $\begin{array}{l}25 \mathrm{~b}-f \\
0 \mathrm{f} \\
0 \mathrm{f} \\
0 \mathrm{f} \\
0 \mathrm{f}\end{array}$ \\
\hline Cluster & $\begin{array}{l}\text { A. alternata } \\
U \text {. atrum }\end{array}$ & $\begin{array}{ll}0 f \\
0 f\end{array}$ & $\begin{array}{l}25 \mathrm{~b}-\mathrm{f} \\
0 \mathrm{f}\end{array}$ & $\begin{array}{l}0 \mathrm{f} \\
50 \text { a-d }\end{array}$ & $\begin{array}{ll}0 f \\
0 f\end{array}$ \\
\hline Root & $\begin{array}{l}\text { A. alternata } \\
\text { C. destructans } \\
\text { Fusarium spp. } \\
\text { M. phaseolina } \\
\text { P. aleophilum } \\
\text { R. solani } \\
\text { U. atrum } \\
\text { Others }\end{array}$ & $\begin{array}{l}0 f \\
18.92 \mathrm{c}-\mathrm{f} \\
0 \mathrm{f} \\
9.22 \mathrm{~d}-\mathrm{f} \\
0 \mathrm{f} \\
1.44 \text { ef } \\
0 \mathrm{f} \\
1.44 \text { ef }\end{array}$ & $\begin{array}{l}0 \mathrm{f} \\
18.17 \mathrm{c}-\mathrm{f} \\
2.37 \text { ef } \\
13.94 \text { d-f } \\
0 \mathrm{ff} \\
0 \mathrm{f} \\
0 \mathrm{f} \\
0 \mathrm{f}\end{array}$ & $\begin{array}{l}0 \mathrm{f} \\
18.32 \text { c-f } \\
31.12 \text { a-e } \\
18.33 \text { c-f } \\
5.38 \text { ef } \\
0 \mathrm{f} \\
0 \mathrm{f} \\
29.76 \text { a-e }\end{array}$ & $\begin{array}{l}1.66 \text { ef } \\
6.53 \text { ef } \\
1.66 \text { ef } \\
5.25 \text { ef } \\
0 \mathrm{f} \\
0 \mathrm{f} \\
8.18 \text { d-f } \\
61.59 \text { a-c }\end{array}$ \\
\hline
\end{tabular}

* Means followed by different letters are significantly different based on Duncan's Multiple Range test $(\mathrm{P}=0.01)$.

** Others:- Represent the percentage of low frequency fungi counted together, include:- Chaetomium elatum, Stachybotrys spp., Drekeslera spp., Pestalatio spp., Epicocum spp., Papulorspora spp., Penicillium spp. Aspergillus spp. Morphotype 1(Colored mycelium with chlamydospores), Morphotype 2 (Sterile mycelium) ${ }^{* \star \star}$ Fusarium spp.: Include F. semitectum (Berkeley and Ravenel F. culmorum (W.G. Smith) Saccardo,F. crookwellense Burgess, Nelson and Toussoun, and F. proliferatum (Matsushima) Nirenberg. 
During spring, B. parva, A. alternata and $C$. destructans were isolated by $75 \%, 25 \%$, and $18.17 \%$ from arms' wood, clusters, and roots respectively. During summer, A. alternata was isolated from arms' bark by $75 \%$ with significant differences from all fungi. In arms' wood the most two common fungi were $B$. parva and $U$. atrum by $11.70 \%$ and $25 \%$ respectively. Trichoderma spp. was detected in canes' bark and leaf by $25 \%$ in each, while $U$. atrum occurred by $50 \%$ in grapevine bud.

Nizarke location: During winter, Phoma spp. and $A$. alternata were the dominant fungi colonized bud and arms' bark (Table 5).

Table (5): Frequency of isolated fungi from different grapevine parts in four seasons at Nizarke location.

\begin{tabular}{|c|c|c|c|c|c|}
\hline Plant part & Isolated fungus & $\begin{array}{l}\text { (Winter) } \\
\text { Dec. - Feb. }\end{array}$ & $\begin{array}{l}\text { (Spring) } \\
\text { Mar. - May }\end{array}$ & $\begin{array}{l}\text { (Summer) } \\
\text { June - Aug. }\end{array}$ & $\begin{array}{l}\text { (Fall) } \\
\text { Sep. - Nov. }\end{array}$ \\
\hline Arms' bark & $\begin{array}{l}\text { A. alternata } \\
\text { Phoma spp. } \\
\text { N. dimidiatum } \\
\text { Others }\end{array}$ & $\begin{array}{l}0 \mathrm{~mA} \\
75 \mathrm{ab} \\
0 \mathrm{~m}-\mathrm{A} \\
0 \mathrm{~m}-\mathrm{A}\end{array}$ & $\begin{array}{ll}0 & \mathrm{~m}-\mathrm{A} \\
0 & \mathrm{~m}-\mathrm{A} \\
0 & \mathrm{~m}-\mathrm{A} \\
75 & \mathrm{ab}\end{array}$ & $\begin{array}{l}0 \mathrm{~m}-\mathrm{A} \\
50 \mathrm{a}-\mathrm{f} \\
0 \mathrm{~m}-\mathrm{A} \\
32.90 \mathrm{c}-\mathrm{k}\end{array}$ & $\begin{array}{l}25 \mathrm{~d}-\mathrm{u} \\
0 \mathrm{~m}-\mathrm{A} \\
9.8 \mathrm{~h}-\mathrm{A} \\
0 \mathrm{~m}-\mathrm{A}\end{array}$ \\
\hline Arms' wood & $\begin{array}{l}\text { A. alternata } \\
B . \text { parva } \\
P . \text { aleophilum } \\
\text { Phoma spp. } \\
\text { N. dimidiatum } \\
\text { Others }\end{array}$ & $\begin{array}{l}0 \mathrm{~m}-\mathrm{A} \\
0 \mathrm{~m}-\mathrm{A} \\
6.70 \mathrm{j}-\mathrm{A} \\
0 \mathrm{~m}-\mathrm{A} \\
56.72 \mathrm{a}-\mathrm{e} \\
26.74 \mathrm{~d}-\mathrm{l}\end{array}$ & $\begin{array}{l}0 \mathrm{~m}-\mathrm{A} \\
11.45 \mathrm{~g}-\mathrm{A} \\
8.44 \mathrm{i}-\mathrm{A} \\
0 \mathrm{~m}-\mathrm{A} \\
39.35 \mathrm{~b}-\mathrm{i} \\
23.02 \mathrm{e}-\mathrm{w}\end{array}$ & $\begin{array}{l}0 \mathrm{~m}-\mathrm{A} \\
33.33 \mathrm{c}-\mathrm{k} \\
37.95 \mathrm{c}-\mathrm{i} \\
0 \mathrm{~m}-\mathrm{A} \\
0 \mathrm{~m}-\mathrm{A} \\
4.15 \mathrm{l}-\mathrm{A}\end{array}$ & $\begin{array}{l}33.87 \mathrm{c}-\mathrm{k} \\
0 \mathrm{~m}-\mathrm{A} \\
0.95 \mathrm{I}-\mathrm{A} \\
9.8 \mathrm{~h}-\mathrm{A} \\
4.15 \mathrm{I}-\mathrm{A} \\
0 \mathrm{~m}-\mathrm{A}\end{array}$ \\
\hline Canes' bark & $\begin{array}{l}\text { A. alternata } \\
\text { Cl. elatum } \\
\text { N. dimidiatum } \\
\text { U. atrum }\end{array}$ & $\begin{array}{l}3.02 \text { I-A } \\
41.32 \text { b-h } \\
25 \mathrm{~d}-\mathrm{u} \\
3.02 \text { I-A }\end{array}$ & $\begin{array}{ll}25 & d-u \\
0 & m-A \\
0 & m-A \\
0 & m-A\end{array}$ & $\begin{array}{lc}0 & m-A \\
0 & m-A \\
0 & m-A \\
25 & d-u \\
\end{array}$ & $\begin{array}{l}0 \mathrm{~m}-\mathrm{A} \\
0 \mathrm{~m}-\mathrm{A} \\
25 \mathrm{~d}-\mathrm{u} \\
6.70 \mathrm{j}-\mathrm{A}\end{array}$ \\
\hline Canes' wood & $\begin{array}{l}\text { A. alternata } \\
P . \text { aleophilum } \\
\text { Phoma spp. } \\
\text { U. atrum } \\
\text { Others }\end{array}$ & $\begin{array}{ll}0 & \mathrm{~m}-\mathrm{A} \\
0 & \mathrm{~m}-\mathrm{A} \\
0 & \mathrm{~m}-\mathrm{A} \\
0 & \mathrm{~m}-\mathrm{A} \\
0 & \mathrm{~m}-\mathrm{A} \\
\end{array}$ & $\begin{array}{ll}0 & \mathrm{~m}-\mathrm{A} \\
0 & \mathrm{~m}-\mathrm{A} \\
0 & \mathrm{~m}-\mathrm{A} \\
0 & \mathrm{~m}-\mathrm{A} \\
0 & \mathrm{~m}-\mathrm{A} \\
\end{array}$ & $\begin{array}{l}0 \mathrm{~m}-\mathrm{A} \\
0 \mathrm{~m}-\mathrm{A} \\
37.31 \mathrm{c}-\mathrm{j} \\
0 \mathrm{~m}-\mathrm{A} \\
38.24 \mathrm{c}-\mathrm{i}\end{array}$ & $\begin{array}{l}36.10 \mathrm{c}-\mathrm{j} \\
21.62 \text { e-x } \\
0 \mathrm{~m}-\mathrm{A} \\
2.37 \mathrm{I}-\mathrm{A} \\
0 \mathrm{~m}-\mathrm{A} \\
\end{array}$ \\
\hline Bud & $\begin{array}{l}\text { A. alternata } \\
\text { Cl. elatum } \\
\text { N. dimidiatum } \\
\text { U. atrum } \\
\text { Others }\end{array}$ & $\begin{array}{l}79.72 \text { a } \\
6.7 \mathrm{j}-\mathrm{A} \\
0 \mathrm{~m}-\mathrm{A} \\
0 \mathrm{~m}-\mathrm{A} \\
0 \mathrm{~m}-\mathrm{A}\end{array}$ & $\begin{array}{ll}6.70 & j-A \\
0 & m-A \\
0 & m-A \\
0 & m-A \\
0 & m-A\end{array}$ & $\begin{array}{lc}0 & \mathrm{~m}-\mathrm{A} \\
0 & \mathrm{~m}-\mathrm{A} \\
0 & \mathrm{~m}-\mathrm{A} \\
0 & \mathrm{~m}-\mathrm{A} \\
25 & \mathrm{~d}-\mathrm{u}\end{array}$ & $\begin{array}{l}5.50 \mathrm{k}-\mathrm{A} \\
0 \mathrm{~m}-\mathrm{A} \\
50 \mathrm{a}-\mathrm{f} \\
5.55 \mathrm{k}-\mathrm{A} \\
5.55 \mathrm{k}-\mathrm{A}\end{array}$ \\
\hline Leaf & $\begin{array}{l}\text { A. alternata } \\
\text { Cl. elatum } \\
\text { Others }\end{array}$ & $\begin{array}{ll}0 & m-A \\
0 & m-A \\
0 & m-A\end{array}$ & $\begin{array}{l}3.02 \mathrm{l}-\mathrm{A} \\
0 \mathrm{~m}-\mathrm{A} \\
6.70 \mathrm{j}-\mathrm{A}\end{array}$ & $\begin{array}{ll}0 & m-A \\
0 & m-A \\
25 & d-u\end{array}$ & $\begin{array}{l}20 \text { e-y } \\
70.33 \text { a-c } \\
0 \text { m-A }\end{array}$ \\
\hline Cluster & Phoma spp. & $0 \mathrm{~m}-\mathrm{A}$ & $0 \mathrm{~m}-\mathrm{A}$ & $25 \mathrm{~d}-\mathrm{u}$ & $0 \mathrm{~m}-\mathrm{A}$ \\
\hline Root & $\begin{array}{l}\text { C. destructans } \\
\text { Cl. elatum } \\
\text { Fusarium spp. } \\
\text { P. aleophilum } \\
\text { R. solani } \\
\text { U. atrum } \\
\text { Others }\end{array}$ & $\begin{array}{l}0 \mathrm{~m}-\mathrm{A} \\
0 \mathrm{~m}-\mathrm{A} \\
33.33 \mathrm{c}-\mathrm{k} \\
0 \mathrm{~m}-\mathrm{A} \\
0 \mathrm{~m}-\mathrm{A} \\
0 \mathrm{~m}-\mathrm{A} \\
30.38 \mathrm{~d}-\mathrm{l}\end{array}$ & $\begin{array}{l}45.47 \mathrm{~b}-\mathrm{g} \\
23.21 \mathrm{e}-\mathrm{v} \\
0 \mathrm{~m}-\mathrm{A} \\
0 \mathrm{~m}-\mathrm{A} \\
17.07 \mathrm{f}-\mathrm{z} \\
1.95 \mathrm{l}-\mathrm{A} \\
0 \mathrm{~m}-\mathrm{A}\end{array}$ & $\begin{array}{l}0 \mathrm{~m}-\mathrm{A} \\
0 \mathrm{~m}-\mathrm{A} \\
62.97 \text { a-d } \\
1.66 \mathrm{I}-\mathrm{A} \\
1.66 \mathrm{I}-\mathrm{A} \\
0 \mathrm{~m}-\mathrm{A} \\
0 \mathrm{~m}-\mathrm{A}\end{array}$ & $\begin{array}{l}75 \mathrm{ab} \\
0 \mathrm{~m}-\mathrm{A} \\
4.15 \mathrm{l}-\mathrm{A} \\
0 \mathrm{~m}-\mathrm{A} \\
0 \mathrm{~m}-\mathrm{A} \\
0 \mathrm{~m}-\mathrm{A} \\
0 \mathrm{~m}-\mathrm{A}\end{array}$ \\
\hline
\end{tabular}

* Means followed by different letters are significantly different based on Duncan's Multiple Range test $(\mathrm{P}=0.05)$.

** Others:- Represent the percentage of low frequency fungi counted together, include:- Chaetomium elatum, Stachybotrys spp., Drekeslera spp., Pestalatio spp., Epicocum spp., Papulorspora spp., Penicillium spp. Aspergillus spp. Morphotype 1 (Colored mycelium with chlamydospores), Morphotype 2 (Sterile mycelium) ${ }^{* * *}$ Fusarium spp.: Include F. semitectum (Berkeley and Ravenel F. culmorum (W.G. Smith) Saccardo,F. crookwellense Burgess, Nelson and Toussoun, and F. proliferatum (Matsushima) Nirenberg. 
In the arms' wood, $N$. dimidiatum occurrence reached to $56.72 \%$. Fusarium spp. was isolated commonly from infected roots by $33.33 \%$. During spring, the highest detection in the infected roots was $C$. destructans $(45.46 \%)$, whereas $N$. dimidiatum continued it's dominance in arms' wood. $P$. aleophilum was also isolated by $8.44 \%$ from arm's wood. During summer, Phoma spp., B. parva, $P$. aleophilum, and Fusarium spp. were isolated by $50 \%$,
$33.33 \%, 37.95 \%$, and $62.97 \%$ from arms' bark, arms' wood, and root respectively.

Zawita location: During winter, A. alternata was found commonly almost in all grapevine parts. The incidence of biocontrol agent Trichoderma spp. was $55.64 \%$ in arms' bark, whereas $B$. parva decreased to $25 \%$ in arms' wood. The frequency of $P$. aleophilum in rotted roots was $22.21 \%$, while $U$. atrum was $29.93 \%$ in canes' wood (Table 6).

Table (6): Frequency of isolated fungi from different grapevine parts in four seasons at Zawita location.

\begin{tabular}{|c|c|c|c|c|c|}
\hline Plant part & Isolated fungus & $\begin{array}{l}\text { (Winter) } \\
\text { Dec. - Feb. }\end{array}$ & $\begin{array}{l}\text { (Spring) } \\
\text { Mar. - May }\end{array}$ & $\begin{array}{l}\text { (Summer) } \\
\text { June - Aug. }\end{array}$ & $\begin{array}{l}\text { (Fall) } \\
\text { Sept. - Nov. }\end{array}$ \\
\hline Arms' bark & $\begin{array}{l}\text { A. alternata } \\
\text { Phoma spp. } \\
\text { Trichoderma spp. } \\
\text { Others }\end{array}$ & $\begin{array}{l}4.15^{*} \mathrm{k}-\mathrm{y} \\
0 \mathrm{n}-\mathrm{y} \\
55.64 \mathrm{a}-\mathrm{f} \\
4.15 \mathrm{k}-\mathrm{y}\end{array}$ & $\begin{array}{ll}0 & n-y \\
0 & n-y \\
0 & n-y \\
0 & n-y\end{array}$ & $\begin{array}{ll}0 & n-y \\
0 & n-y \\
0 & n-y \\
0 & n-y\end{array}$ & 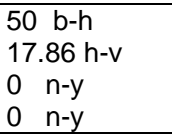 \\
\hline Arms' wood & $\begin{array}{l}\text { A. alternata } \\
\text { B. parva } \\
\text { Cl. elatum } \\
P . \text { aleophilum } \\
\text { Phoma spp. } \\
\text { Trichoderma spp. } \\
\text { U. atrum } \\
\text { Others }\end{array}$ & $\begin{array}{l}24.50 \text { e-q } \\
25 \text { e-o } \\
6.70 \text { k-y } \\
0 \text { n-y } \\
0 \text { n-y } \\
0 \text { n-y } \\
0 \quad n-y \\
5.55 \quad k-y\end{array}$ & 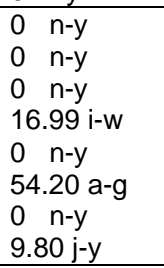 & $\begin{array}{l}22.15 \mathrm{f}-\mathrm{s} \\
6.70 \mathrm{k}-\mathrm{y} \\
0 \quad \mathrm{n}-\mathrm{y} \\
27.96 \mathrm{~d}-\mathrm{I} \\
0 \mathrm{n}-\mathrm{y} \\
0 \mathrm{n}-\mathrm{y} \\
6.70 \mathrm{k}-\mathrm{y} \\
0 \mathrm{n}-\mathrm{y} \\
\end{array}$ & $\begin{array}{l}27.82 \mathrm{~d}-\mathrm{I} \\
0 \mathrm{n}-\mathrm{y} \\
0 \mathrm{n}-\mathrm{y} \\
36.81 \mathrm{c}-\mathrm{j} \\
18.47 \mathrm{~h}-\mathrm{u} \\
0 \mathrm{n}-\mathrm{y} \\
0 \mathrm{n}-\mathrm{y} \\
16.66 \mathrm{i}-\mathrm{x}\end{array}$ \\
\hline Canes' bark & $\begin{array}{l}\text { A. alternata } \\
\text { Phoma spp. } \\
\text { U. atrum } \\
\text { Others }\end{array}$ & $\begin{array}{l}55.64 \text { a-f } \\
0 \mathrm{n}-\mathrm{y} \\
0 \mathrm{n}-\mathrm{x} \\
4.15 \mathrm{k}-\mathrm{y}\end{array}$ & $\begin{array}{ll}0 & n-y \\
0 & n-y \\
0 & n-y \\
0 & n-y \\
\end{array}$ & $\begin{array}{ll}0 & n-y \\
0 & n-y \\
0 & n-y \\
0 & n-y\end{array}$ & $\begin{array}{l}25 \text { e-o } \\
25 \text { e-o } \\
5.55 \mathrm{k}-\mathrm{y} \\
57.11 \mathrm{a}-\mathrm{e}\end{array}$ \\
\hline Canes' wood & $\begin{array}{l}\text { A. alternata } \\
B . \text { parva } \\
\text { Cl. elatum } \\
\text { P. aleophilum } \\
\text { Trichoderma spp. } \\
U \text {. atrum } \\
\text { Others }\end{array}$ & $\begin{array}{l}29.95 \mathrm{c}-\mathrm{k} \\
0 \mathrm{n}-\mathrm{y} \\
5.50 \mathrm{l}-\mathrm{y} \\
0 \mathrm{n}-\mathrm{y} \\
3.49 \mathrm{l-y} \\
29.93 \mathrm{c}-\mathrm{k} \\
20.95 \mathrm{~g}-\mathrm{t}\end{array}$ & $\begin{array}{ll}0 & n-y \\
0 & n-y \\
10.86 & j-y \\
0 & n-y \\
0 & n-y \\
0 & n-y \\
75 & a b\end{array}$ & $\begin{array}{l}0 \text { n-y } \\
58.68 \text { a-e } \\
3.02 \text { m-y } \\
0 \text { n-y } \\
0 \text { n-y } \\
0 \text { n-y } \\
0 \text { n-y }\end{array}$ & $\begin{array}{ll}0 & n-y \\
0 & n-y \\
0 & n-y \\
75 & a b \\
0 & n-y \\
0 & n-y \\
0 & n-y\end{array}$ \\
\hline Bud & $\begin{array}{l}\text { A. alternata } \\
\text { B. parva } \\
\text { Cl. elatum } \\
\text { Trichoderma spp. } \\
\text { U. atrum } \\
\text { Others }\end{array}$ & $\begin{array}{l}61.15 \text { a-d } \\
2.37 \mathrm{~m}-\mathrm{y} \\
2.37 \mathrm{~m}-\mathrm{y} \\
0 \mathrm{n}-\mathrm{y} \\
5.55 \mathrm{k}-\mathrm{y} \\
7.84 \mathrm{k}-\mathrm{y}\end{array}$ & $\begin{array}{l}0 \text { n-y } \\
4.75 \text { k-y } \\
4.75 \text { k-y } \\
25 \text { e-o } \\
0 \text { n-y } \\
3.02 \text { m-y }\end{array}$ & $\begin{array}{ll}0 & n-y \\
0 & n-y \\
0 & n-y \\
0 & n-y \\
0 & n-y \\
0 & n-y\end{array}$ & $\begin{array}{ll}0 & n-y \\
0 & n-y \\
0 & n-y \\
0 & n-y \\
0 & n-y \\
0 & n-y\end{array}$ \\
\hline Leaf & $\begin{array}{l}\text { A. alternata } \\
\text { Cl. Elatum }\end{array}$ & $\begin{array}{ll}0 & n-y \\
0 & n-y\end{array}$ & $\begin{array}{l}6.70 \text { k-y } \\
6.70 \text { k-y }\end{array}$ & $\begin{array}{ll}0 & n-y \\
0 & n-y\end{array}$ & $\begin{array}{l}83.10 \mathrm{a} \\
83.33 \mathrm{a}\end{array}$ \\
\hline Root & $\begin{array}{l}\text { A. alternata } \\
\text { C. destructans } \\
\text { Cl. elatum } \\
\text { Fusarium spp. } \\
\text { M. phaseolina } \\
P . \text { aleophilum } \\
\text { R. solani } \\
\text { Trichoderma spp. } \\
\text { U. atrum } \\
\text { Others }\end{array}$ & 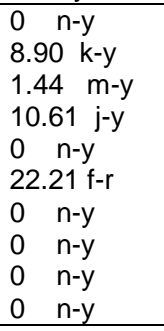 & $\begin{array}{l}0 \text { n-y } \\
5.12 \text { k-y } \\
0 \text { n-y } \\
7.38 \text { k-y } \\
0 \text { n-y } \\
7.38 \text { k-y } \\
4.75 \text { k-y } \\
4.75 \text { k-y } \\
0 \text { n-y } \\
2.37 \text { m-y }\end{array}$ & $\begin{array}{l}0 \text { n-y } \\
1.33 \mathrm{~m}-\mathrm{y} \\
0 \mathrm{n}-\mathrm{y} \\
1.44 \mathrm{~m}-\mathrm{y} \\
5.36 \mathrm{k}-\mathrm{y} \\
0 \mathrm{n}-\mathrm{y} \\
0 \mathrm{n}-\mathrm{y} \\
0 \mathrm{n}-\mathrm{y} \\
0 \mathrm{n}-\mathrm{y} \\
62.84 \mathrm{a}-\mathrm{c}\end{array}$ & $\begin{array}{l}1.44 \text { m-y } \\
42.64 \text { b-i } \\
0 \text { n-y } \\
0 \text { n-y } \\
7.24 \text { k-y } \\
0 \text { n-y } \\
0 \text { n-y } \\
0 \text { n-y } \\
0 \text { n-y } \\
60.48 \text { a-d }\end{array}$ \\
\hline
\end{tabular}

* Means followed by different letters are significantly different based on Duncan's Multiple Range test $(\mathrm{P}=0.05)$.

** Others:- Represent the percentage of low frequency fungi counted together, include:- Chaetomium elatum, Stachybotrys spp., Drekeslera spp., Pestalatio spp., Epicocum spp., Papulorspora spp., Penicillium spp. Aspergillus spp. Morphotype 1 (Colored mycelium with chlamydospores), Morphotype 2 (Sterile mycelium) ${ }^{* * *}$ Fusarium spp.: Include F. semitectum (Berkeley and Ravenel F. culmorum (W.G. Smith) Saccardo, F. crookwellense Burgess, Nelson and Toussoun, and F. proliferatum (Matsushima) Nirenberg. 
Agric. Biol. J. N. Am., 2013, 4(3): 336-348

During spring, results revealed that Trichoderma spp. occurred significantly by $54.20 \%$ and $25 \%$ in arms' wood and buds respectively. This high occurrence was in agreement with Larignon et al. (2001) who isolated $T$. harzianum from the arms' wood in Bordeaux area- France by $39.1 \%$. P. aleophilum was isolated by $16.99 \%, 4.75 \%$ from arms' wood and grapevine root respectively. $B$. parva and $C$. destructans occurred by $4.57 \%$ and $5.12 \%$ in the buds and roots respectively.

During summer, the dominant fungi in arms' wood were $P$. aleophilum and $A$. alternata while in canes' wood was $B$. parva. During fall, results revealed that $P$. aleophilum appeared significantly in canes' wood by $75 \%$, it was also found in arms' wood by $36.81 \%$.

The survey presented here allowed us to obtain more information about the etiology of the fungal pathogens associated with grapevine decline .We detected the presence of $B$. parva, $P$. aleophilum, and $C$. destructans almost along survey period. This study provides evidence for the presence of these pathogens in Iraqi grape vineyards as it has been described in other countries (Halleen et al., 2003; Fourie and Halleen, 2004).

These results indicated that the isolation frequency of fungi varied during the growing season in each location; this might be due to cultivar susceptibility, training method, or irrigation systems.

Plant age (ranging $10-15$ years in the surveyed locations) might have been a factor for esca development combined by $P$. aleophilum. Since, Mugnai et al (1999) found that $4-5$ year old vines sometimes show foliar symptoms of esca, it is only on 10- year old plants or older that symptoms and damage become more common. This age factor was related by Viala (1926) to tannin levels in the plants. These levels increase from 12 to 13 years until 25 to 30 years, which was also the case when the vines showed internal and external esca symptoms with the highest frequency and severity.

\section{Phenotypical characterization}

Phaeoacremonium aleophilum W. Gams, Crous, M. J. Wingf. et L. Mugnai. Mycologia 88:791 (1996).

Fig. (1) A - E.
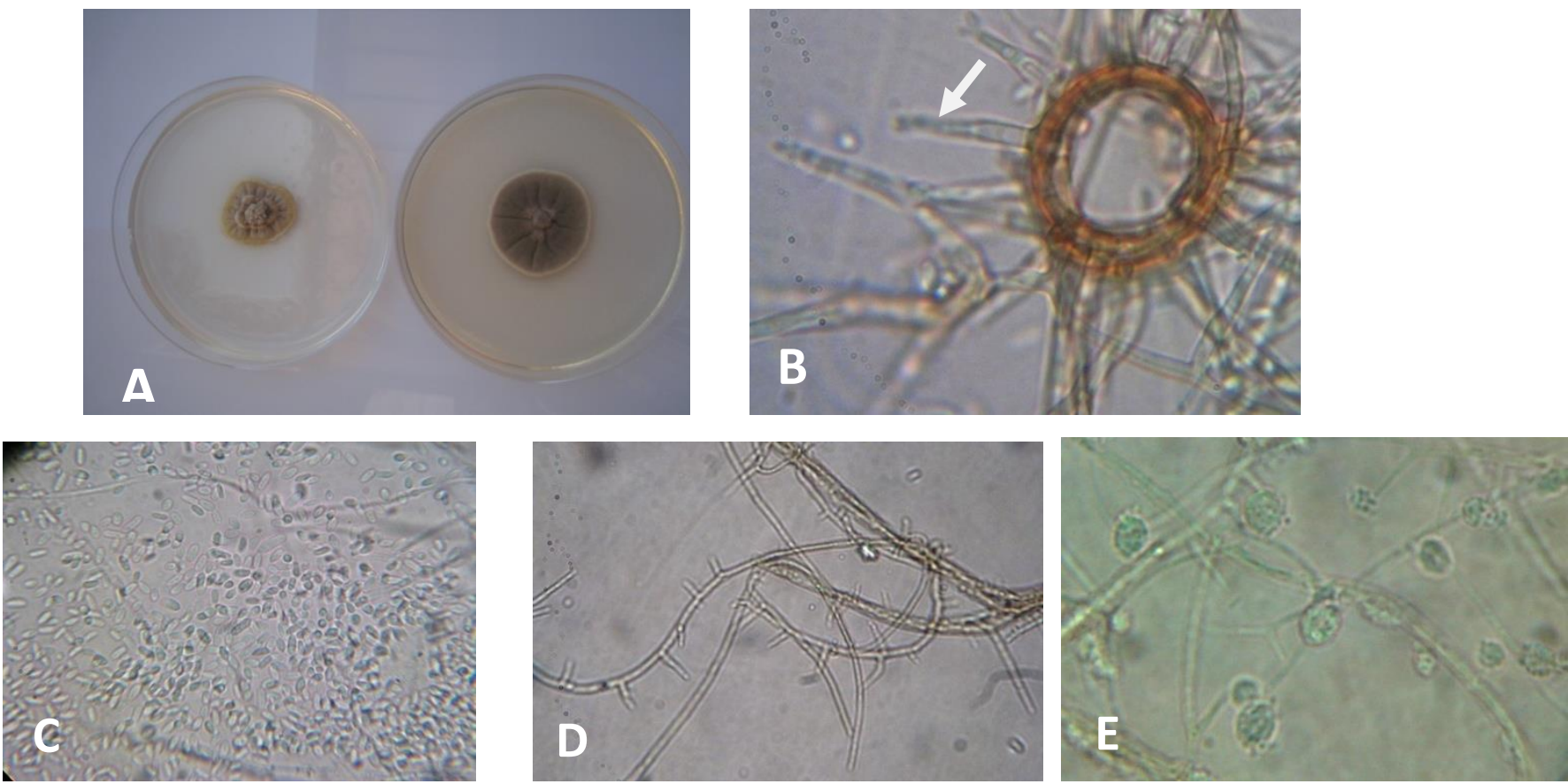

Fig. (1): Phaeoacremonium aleaophilum, A) Twenty- day old colony on MEA-left, and PDA-right B) Type II Phialides C) Conidia.Scale bar: $5 \mu \mathrm{m}$. D) Mycelium with phialide E) Structures on the surface of and in MEA. Adelophialide with conidia. Scale bar: $5 \mu \mathrm{m}$., Scale bars of $B$ applies to D - E. 
Telemorph: Togninia minima (Tul.and C. Tul.) Berl., Icon. Fung. (Abellini) 3:9 (1900).

Cultural characters: colonies on MEA, reached a diameter of $22 \mathrm{~mm}$ after 20 days of incubation at $25^{\circ} \mathrm{C}$. Flat, mostly felty texture with entire edge, Pale yellow color in above and in reverse. Colonies on PDA, reached a radial of $25.5 \mathrm{~mm}$ after 20 days. Flat, wooly texture with entire edge, Dark blond to brownish grey towards the edge above, in reverse pale brown to dark brown towards the edge.

Aerial structure: Hyphae are verruculose, medium to pale brown, and $1.5-2.5 \mu \mathrm{m}$ wide. Conidiophores are mostly short and usually unbranched, 0-3 septate. 17 - $29 \mu \mathrm{m}$ long and 2 - $2.5 \mu \mathrm{m}$ wide. The apical cell of conidiophores usually produces one phialide. Phialides terminal or lateral, mostly monophialidic, smooth to verreculose, subhyline; type II and type III phialides are most common. Type I phialides are cylindrical occasionally wider at the base, $4-9 \times 1-1.5 \mu \mathrm{m}$ (av. $5 \times 1.5) \mu \mathrm{m}$. Type II phialides are either elongate-ampulliform and attenuated at the base or are navicular, tapering towards the apex, 10-14 × 1.5-2.5 $\mu \mathrm{m}$ (av. $11 \times 2$ ) $\mu \mathrm{m}$. Type III phialides are subcylindrical or elongate ampulliform and attenuated at the base, $15-20 \times 1.5$ - $2 \mu \mathrm{m}$ (av. $18 \times 2$ ) $\mu \mathrm{m}$. Conidia are mostly oblongellipsoidal or cylindrical, $2.5-6 \times 1-2 \mu \mathrm{m}$ (av. $3.5 \times$ 1.5) $\mu \mathrm{m}$. This description was in agreement with the other in rstigations (Crous et al., 1996; Mostert et al., 2005b; and Mostert, 2006).

Botryosphaeria parva, Pennycook and Samuels. Mycotaxon 24:455 (1985). Anamorph: Neofusicoccum parvum (Pennycook \& Samuels) Crous, Slippers \& A.J.L. Phillips. Studies in mycology 55: 248 (2006). Fig. (2) A-D.
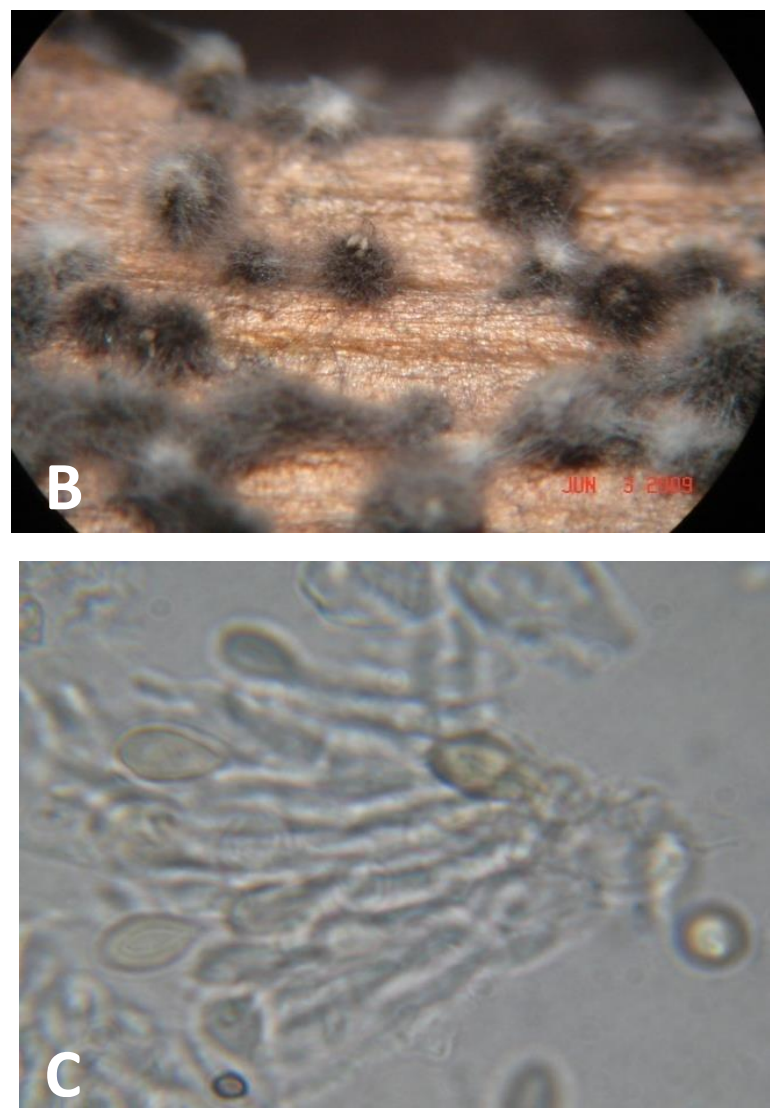

Fig (2): A) Colony of Botryosphaeria parva on MEA -left, PDA-right, after 10 days of incubation at $25^{\circ} \mathrm{C}$. B) Pycnidia of $B$. parva in different stages on the surface of grapevine canes bark. C-D) Conidiogenous cells hyaline, holoblastic forming conidia at their tips discharged from mature pycnidium. Scale bars: $C=20 \mu \mathrm{m}$. $\mathrm{D}=10 \mu \mathrm{m}$. 
Based on morphological characters all isolates of Botryosphaeria species were identified as Botryosphaeria parva Pennycook and Samuels. The Colony diameter reached $90 \mathrm{~mm}$ on PDA and MEA after $10 \mathrm{~d}$ of incubation at $25^{\circ} \mathrm{C}$. Colonies on PDA formed abundant aerial mycelium that was initially white but turned dark-olivaceous after $5-6 \mathrm{~d}$ at $25^{\circ} \mathrm{C}$. The reverse side was almost black in older cultures. Pycnidia usually were aggregated and appeared after 20-25 d in cultures incubated under black light with a $12 \mathrm{~h}$ photoperiod and appeared on the moist cane's bark after 30 days under room temperature. Conidiophores were reduced to conidiogenous cells. Conidiogenous cells hyaline, holoblastic forming conidia at their tips. Conidia hyaline, guttulate, thin- walled, non-septate, smooth, fusiform to ellipsoidal with a subobtuse apex and truncate or rounded base, often with a minute basal frill. Conidia frequently become olivaceous or light brown. Measurements of conidial dimensions of our isolates were in line with those reported by others (Pennycook and Samuels, 1985; Phillips, 2002; Slipper et al, 2005; and Urbez-Torres, 2006).

Cylindrocarpon destructans (Zinssm.) Scholten, Neth. JL. PL. Path. 70 (Suppl. 2) 9 (1964).

Fig. (3) A - D. Telemorph: Neonectria radicicola (Gerlach and L. Nillsson) Mantiri and Samules.Canada J. Bot. 79: 339 (2001).
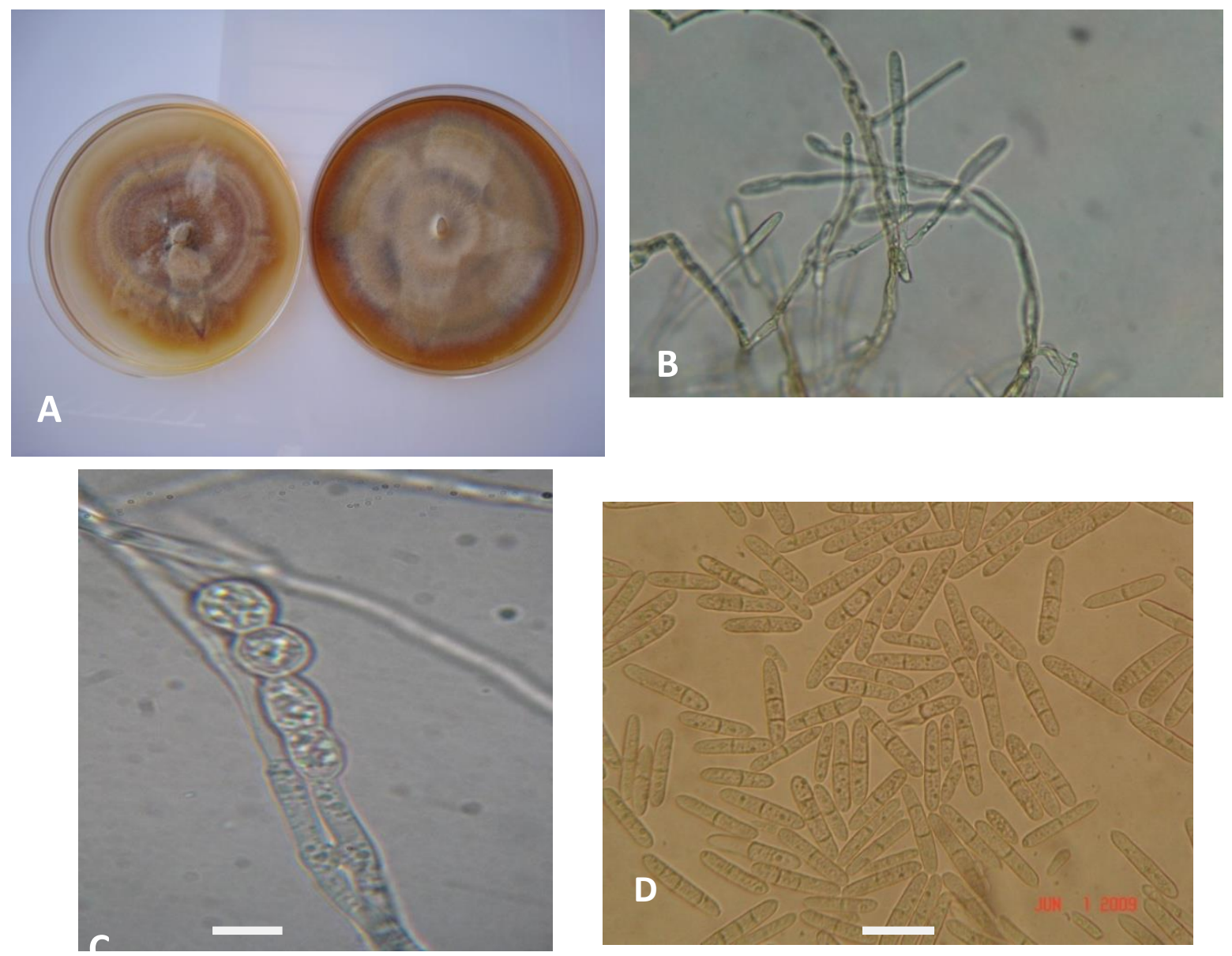

Fig (3): A) Colony of Botryosphaeria parva on MEA -left, PDA-right, after 10 days of incubation at $25^{\circ} \mathrm{C}$. B) Pycnidia of $B$. parva in different stages on the surface of grapevine canes bark. C-D) Conidiogenous cells hyaline, holoblastic forming conidia at their tips discharged from mature pycnidium. Scale bars: $C=20 \mu \mathrm{m} . \mathrm{D}=10 \mu \mathrm{m}$ 
Colonies on MEA reached a diameter of $78 \mathrm{~mm}$ on PDA and $80 \mathrm{~mm}$ on MEA after 20 days at $25^{\circ} \mathrm{C}$. Colony surface slimy to felty; aerial mycelium typically sparse to felty, white to buff or a shade of brown. Colony reverse was orange to dark brown. Slimy sporodochia usually abundant on the colony surface and in the aerial mycelium, often forming in concentric rings. Conidiogenous cells formed apically on densely, irregularly branching clusters of cells borne laterally on otherwise undifferentiated vegetative hyphae. Conidiophores $65 \mu \mathrm{m}$ tall. Macroconidia cylindrical, mainly 4-celled, 18 - 45 (47) $\times 4-8 \mu \mathrm{m}$. Microconidia, cylindrical, 1-celled, 8 $11(-12) \times 3-4 \mu \mathrm{m}$. Chlamydospores yellowish brown, ovate to ellipsoidal, a few in a chain, $\mathrm{C}^{\prime}$ lamydospores $8-10(-15) \mu \mathrm{m}$ in diamete Conidial dimensions were in concordance with the previous identification (Petit and Gubler, 2005).

\section{REFERENCES}

Armengol , .J., A. Vicent, L. Torné, F.García-Figueres and J. García-Jeménez, 2001. Fungi associated with esca and grapevine declines in Spain: a three-year survey. Phytopathologia Mediterranea. 40:325-329.

Auger J., A. Droguett and M. Esterio, 1999. The red Glob Decline. In: Proceeding of the first international Workshop on grapevine Trunk Diseases: Esca and grapevine declines 1-3 October, Siena, Italy.

Boerema G.H., 1993. Contribution towards a monograph of Phoma (coelomyces) II. section: peynonellaea. Persoonia. 15:197-221.

Castillo-Pando M., A. Somers, C. D. Green, M. Priest arıü M. Sriskanthades, 2001. Fungi associated with dieback of Semillon grapevines in the Hunter Valley of New South Wales. Aust. Plant Path. 30:59-63.

Creaser, M. and T. Wicks, 2001. Yearly variation in Eutypa dieback symptoms and the relationship to grapevine yield. The Australian and New Zealand Grapegrower and Winemaker 452: 50-52.

Crous P.W., W. Gams, M.J. Wingfield and P.S. Van Wyk, 1996. Phaeoacremonium gen. nov. associated with wilt and decline diseases of woody hosts and human infections. Mycologia 88: 786-796.

Domsch K.H., W. Gams and T.H. Anderson, 1980. Compendium of soil fungi. vol. I. Academic press. UK.

Edwards J., G. Marchi and I. Pascoe, 2001. Young esca in Australia. Phytopathologia Mediterranea 40: 303310.

Ellis M. B, 1971. Demataceous Hyphomycetes. CMI. Kew, U.K.

F.A.O., 2003. The (UN) Bulletin of statistics, Vo. 14,No.2.
Fourie P.H. and F. Halleen, 2004. Occurrence of grapevine trunk disease pathogens in rootstock mother plants in South Africa. Australas Plant Pathol 33: 313-315.

Gubler W.D., T.S. Thind, A.J. Feliciano and A. Eskalen, 2004. Pathogenicily of Phaeoacremonium spp. and Phaeomoniella chlamydospora on grape berries in California Phytopathol. Mediterr. 43:70-74.

Halleen F., P. W. Crous and O. Petrini, 2003. Fungi associated with healthy grapevine cuttings in nurseries, with special reference to pathogens involved in the decline of young vines. Australas Plant Pathol. 32: 47-52.

Halleen F., P.H. Fourie and P.W. Crous, 2006. A review of black foot disease of grapevine. Phytopathologia Mediterranea 45: 55-67.

Larignon P., 1999. Black foot disease in France. In: Black Goo Occurrence and Symptoms of Grapevine Declines - IAS/ICGTD Proceedings 1998. (L. Morton ed.), International Ampelography Society, Fort Valley, VA, USA, p. 89-90.

Larignon P. and B. Dubos, 1997. Fungi associated with esca disease in grapevine. Eur. J. Plant Pathol. 103: 147-157.

Larignon P. and B. Dubos, 2000. Preliminary studies on the biology of Phaeoacremonium. Phytopathologia Mediterranea 39: 184-189.

Luque J., S. Martos and A. J. L. Phillips, 2005. Botryosphaeria viticola sp. nov. on grapevines: a new species with a Dothiorella anamorph. Mycologia 97:1111-1121.

Martin M. T. and R. Cobos, 2007. Identification of fungi associated with grapevine decline in Castilla y León (Spain). Phytopathologia Mediterranea 46, 18-25.

Michenny, H. H., 1923. Influence of soil temperature and moisture on infection of wheat seedling by Helminthosporium sativum. J. Agri. Res. 26:195-217.

Mostert L., 2006. Phylogeny and taxonomy of Phaeoacremonium and its relatives, Ph.D. Thesis, Wagenningen University, The Netherlands.

Mostert L., W. Gams and P.W. Crous, 2005a. New teleomorph findings for species in the genus Phaeoacremonium. Phytopathologia Mediterranea 44: 91 (abstract).

Mostert L., J. Z. Groenewald, R.C. Summerbell, R.V., D.A. Sutton, A. A. Padhye and P.W. Crous, 2005b. Species of Phaeoacremonium associated with human infections and environmental reservoirs in infected woody plants. J. Clin. Microbiol. 43: 1752-1767.

Mugnai L., A. Graniti and G. Surico, 1999. Esca (Black measles) and brown wood streaking: two old and elusive disease of grapevines. Plant Dis. 83: 404418. 
Oliveira H., C. Rego and T. Nascimento, 2004. Decline of young grapevines caused by fungi. Acta Horticulturae 652:295-304.

Pennycook, S. R.; G. J. Samuels. (1985). Botryosphaeria and Fusicoccum species associated with ripe fruit rot of Actinidia deliciosa (Kiwifruit) in New Zealand. Mycotaxon 24:445-458.

Petit E. and W.D. Gubler, 2005. Characterization of Cylindrocarpon species, the cause of black foot disease of grapevine in California. Plant Dis. 89:10511059.

Phillips A.J.L., 1998. Botryosphaeria dothidea and other fungi associated with Excoriose and dieback of grapevines in Portugal. J. Phytopathol. 146: 327332.

Phillips A.J.L., 2002. Botryosphaeria species associated with diseases of grapevines in Portugal. Phytopathologia Mediterranea 41: 3-18.

Rego C., H. Oliveira, A. Carvalho and A. Phillips, 2000. Involvement of Phaeoacremonium spp. and Cylindrocarpon destructans with grapevine decline in Portugal. Phytopathologia Mediterranea 39: 76-79.

Rumbos I. and A. Rumbou, 2001. Fungi associated with esca and young grapevine decline in Greece. Phytopathologia Mediterranea 40: 330-335.

Saido K.A., 2007. Fungal Decline of Grapevines in Dohuk Provines. M.Sc. thesis. College of Agriculture, University of Duhok.

Samson R.A., E.S. Hoekstra, J. C. Frisvad and O. Filtenborg, 2000. Introduction to food and airborne fungi. CBS, Utrecht, Netherlands
SAS, 1999. SAS/STAT User's Guide, Version 8.2, 1st printing. Vol. 2. SAS Institute Inc, SAS Campus Drive, Gary, North Carolina.

Scheck H.J., S.J. Vasquez and W.D. Gubler, 1998a. First report of black-foot disease, caused by Cylindrocarpon obtusisporum, of grapevine in California. Plant Dis. 82: 448.

Scheck H.J., S.J. Vasquez and W.D. Gubler, 1998b. First report of three Phaeoacremonium spp. causing young grapevine decline in California. Plant Dis. 82: 590 (abstract).

Slippers1 B ., I. G. Johnson, P. W. Crous, T. A. Coutinho, B. D. Wingfield and M. J. Wingfield, 2005. Phylogenetic and morphological re-evaluation of the Botryosphaeria species causing diseases of Mangifera indica. Mycologia 97:99-110.

Sweetingham M.,1983. Studies on the nature and pathogenicity of soilborne Cylindrocarpon spp. Ph.D. Thesis, University of Tasmania.

Úrbez-Torres J.R., G.M. Leavitt, T.M. Voegel and W. D. Gubler, 2006. Identification and distribution of Botryosphaeria spp. associated with grapevine cankers in California. Plant Dis. 90:1490-1503.

Viala P., 1926. Recherces sur les maladies de la vigne. Esca. Ann. Épiphyt. 12,5-108. cited by: Mugnai, L.; A. Graniti and G. Surico. (1999). Esca (black measles) and brown wood-streaking: two old and elusive diseases of grapevines. Plant Dis. 83:404 - 418.

Watanabe T., 2002. Pictorial atlas of soil and seed fungi: Morphologies of cultured fungi and key to species $\left(2^{\text {nd }}\right.$ ed.) CRC Press. 486pp. 